of Denison and colleagues are not major (see below). Our technique is based on a general evaluation of gas behaviour during the several phases of respiration.' Hence all equations are absolute closed solutions for each phase of breathing. Like the approach of Denison and colleagues, we correct for uneven volume to function by dividing instantaneous absorbable gas concentrations (carbon monoxide, acetylene) by simultaneous inert gas (helium) concentration. Mild to moderate maldistribution does not affect the accuracy of the technique. In the nine patients in whom single breath nitrogen values were measured the mean (SD) values were $4.11 \%(2.84 \%) / 1$ (range 0.5 $8.4 \%$ ) in seven (of 20 ) who had reproduceable values and $6.8 \%$ and $16.4 \% / 1$ in two (of three) who did not have reproduceable values.

Secondly, while it is quite true that high inspiratory flow rates lead to more even distribution of boluses of gas inspired at several lung volumes, ${ }^{23}$ the effects of this phenomenon on gas absorption test results may not be easy to predict for near vital capacity breaths, particularly in the presence of "normal" regional non-uniformity of blood flow. ${ }^{4}$ In fact, the mean (SD) inspiratory flow rate of our patients was $0.60(0.22) 1 / \mathrm{s}$. This flow rate is moderately low when compared with the data in the reference. ${ }^{23}$

Thirdly, we apologise for the typographical error in the equation on $p 108$ of our article. The first $\alpha_{t}$ should read $\alpha_{b}$ (Bunsen coefficient for blood).

Finally, the article by Dr Corris and his associates, unfortunately, has not, as yet, reached California. We look forward to reading this work with great interest.

We wish to thank Professor Denison and Dr Waller for their comments. They have highlighted several interesting and important points which we would like to try to address. After carefully reading the paper of Denison and colleagues $^{5}$ we agree that their technique has a large number of similarities to our technique, including the choice of gases, respiratory manoeuvres, and, perhaps, the theoretical approach. Equation 3 in their paper is:

$$
\frac{-\mathrm{dP}_{\mathrm{A}}}{\mathrm{dt}} \beta \mathrm{g} \mathrm{V}_{\mathrm{A}}(\mathrm{t})=G P_{A}
$$

where $G$ is pulmonary blood flow, $\beta \mathrm{g}$ a comparative term, and $V_{A}(t)$ alveolar volume at any time. Later in the paper they state that initial gas volume must be corrected for an equivalent lung tissue volume which has reached equilibration with end inspiratory gas. In our theoretical paper ${ }^{6}$ we are more explicit (equation 9, rearranged to be similar to that of Denison and colleagues):

$$
\frac{\mathrm{dF}_{\mathrm{A}}}{\mathrm{dt}}\left(\mathrm{V}_{\mathrm{A}}+{ }_{\mathrm{t}} \mathrm{V}_{\mathrm{t}}\right)=\alpha_{\mathrm{b}} \dot{\mathrm{Q}}_{\mathrm{c}} \mathrm{F}_{\mathrm{A}} \text {; }
$$

the symbols are defined in both the earlier theoretical paper $^{1}$ and our more recent validation paper. ${ }^{6}$ One apparent difference between the approaches is that the term for gas equivalent volume of tissue, $\alpha_{t} V_{t}$, is utilised at all alveolar volumes in our technique and, perhaps, only at end inspiratory gas volume in their technique. For further comparison between techniques, it would be useful to know what solution of the differential equation they utilise for actual calculation of Q́c. Nevertheless, Denison and Waller are quite correct in their assertion of similarity.
Our experiences with these similar techniques have, however, not been identical. We have noted progressive systematic reduction of $Q c$ values when repeat estimations are performed after less than a 15 minute wait; we allow an additional five minute wait to be sure that the rate of absorption of acetylene will not be reduced by retained gas. Finally, we have not felt confident in applying this technique to patients with severe airways obstruction and markedly abnormal distribution of volume, ventilation, and perfusion. We have frequently noted curvilinear relationships in these patients and feel that validation by direct measurement is indicated before the technique can be widely applied in such patients.

$$
\begin{array}{r}
\text { AF WILSON } \\
\text { URI ELKAYAM } \\
\text { University of Southern California } \\
\text { School of Medicine } \\
101 \text { City Drive South } \\
\text { Orange, California 92668 }
\end{array}
$$

USA

' Martonen TB, Wilson AF. Theoretical basis of single breath gas absorption tests. J Math Biol 1982;14:203-20.

${ }^{2}$ Robertson PC, Anthonisen NR, Ross D. Effect of inspiratory flow rate on regional distribution of inspired gas. J Appl Physiol 1969;26:438-44.

${ }^{3}$ Connolly T, Bake L, Wood L, Milic Emili J. Regional distribution of a ${ }^{133} \mathrm{Xe}$ labelled gas volume inspired at constant flow rates. Scand J Respir Dis 1975;56:150-9.

${ }^{4}$ West JB. Ventilation 2nd ed. Oxford: Blackwell, 1970.

${ }^{5}$ Denison DM, Davies NJH, Meyer M, Pierce RJ, Scheid P. Single-exhalation method for study of lobar and segmental lung function by mass spectrometry in man. Respir Physiol 1980; 42:87-99.

- Elkayam U, Wilson AF, Morrison J, Meltzer P, Davis J, Kosterman P, Louvier J, Henry WJ. Non-invasive measurement of cardiac output by a single breath constant expiratory technique. Thorax 1982;39:107-13.

\section{Riedel's thyroiditis with multiple organ fibrosis}

Sir,-In 1981 we reported a man with Riedel's thyroiditis who had extensive fibrosis in the upper parts of both lungs.' We now record the postmortem findings.

He presented in 1962 with a small lump in the thyroid and a diagnosis of Riedel's thyroiditis was made after biopsy. A chest radiograph was reported to show apical pleural thickening and by 1968 there were large opacities in the upper parts of both lungs. These increased in size and he became increasingly short of breath. He eventually developed right heart failure and he died with bronchopneumonia in December 1983 at the age of 80 .

At postmortem examination the thyroid was replaced by dense fibrous tissue, which was constricting the trachea and infiltrating the strap muscles. The upper lobes, the right middle lobe, and the apical segment of the lower lobes were also replaced by fibrous tissue, which obliterated the adjacent pleural space (fig). Sections of this tissue show coarse interweaving bundles of collagen fibres, containing occasional fibroblasts, small lymphocytes, and small blood vessels. There was no continuity of fibrosis between the thyroid and the lungs. The caudal areas of lungs showed 
patchy bronchopneumonia and compensatory emphysema. The overlying pleura was normal. The transition between normal and abnormal tissue was abrupt and sections at the junction showed a zone of younger collagen $2 \mathrm{~mm}$ wide, with hyperaemia and light lymphocytic infiltration. The hilar lymph nodes were enlarged and reactive.

Two sharply demarcated areas of fibrosis each $2 \mathrm{~cm}$ in maximum diameter were present in the right kidney and a further focus almost entirely replaced the pituitary. Again there were narrow bands of hyperaemia and lymphocytic infiltrate at the junction with normal tissues. There was no fibrosis in the retroperitoneum or mediastinum, or in the neck away from the thyroid. The right ventricle was enlarged.

In Riedel's thyroiditis there is dense fibrosis of the gland that often spreads to adjacent tissues, especially the strap muscles. In a few cases fibrosis has also been found in other areas, including retroperitoneal tissues, ${ }^{2}$ mediastinum, ' orbit,' lacrimal glands, ${ }^{3}$ parotid gland, ${ }^{4}$ and biliary tree (sclerosing cholangitis). ${ }^{1}$ We have seen no reports of fibrosis in lungs, kidney, or pituitary. At the time of our original report we believed that the fibrosis was spreading

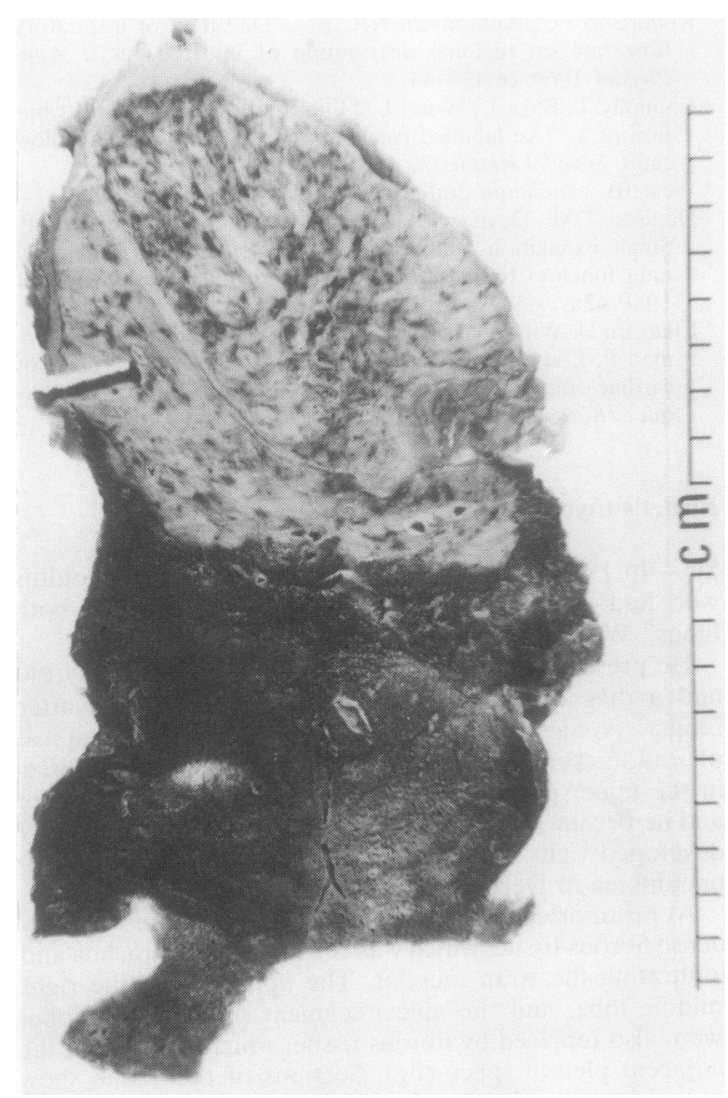

Sagittal section of the left lung, showing fibrosis of upper lobe and apex of the lower lobe, obliteration of the interlobar fissure, and sharp transition to comparatively normal lung. downwards from the thyroid to invade the lungs but it is now evident that there were separate areas of fibrosis in? the lungs, kidney, and pituitary.

Our patient and the others referred to above had not $\frac{\bar{s}}{2}$ taken methysergide or practolol, and drug induced $\mathbb{Q}$ retroperitoneal fibrosis seems to be a different condition.0 The familial form ${ }^{5}$ may also be distinct. This case supports? Mitchinson's view that Riedel's thyroiditis is part of a spec-. trum of a disease that he describes as systemic idiopathic $\overrightarrow{-}$ fibrosis. ${ }^{6}$

$$
\begin{aligned}
& \text { D DAVIES } \\
& \text { P FURNESS }
\end{aligned}
$$

1 Ward MJ, Davies D. Riedel's thyroiditis with invasion of the lungs. Thorax 1981;36:956-7.

2 Rao C, Ferguson GC, Kyle UN. Retroperitoneal fibrosis associated with Riedel's struma. Can Med Assoc J 1973; 108:1019-21.

3 Sclare G, Luxton RW. Fibrosis of the thyroid and lacrimal尺 glands. Br J Ophthalmol 1967;51:173-7.

4 Hines RC, Scheuermann HA, Royster HP, Rose ER. Invasive fibrous (Riedel's) thyroiditis with bilateral fibrous parotitis. JAMA 1970;213:869-74.

5 Comings DE, Skubi KB, Van Eyes J, Motulski AG. Familialp multifocal fibrosclerosis. Am Intern Med 1967;66:884-92.

6 Mitchinson MJ. The pathology of idiopathic retroperitoneal fibrosis. J Clin Pathol 1970;23:681-9.

\section{Notices}

\section{Postgraduate course on lung pathology}

A course on lung pathology will be held under the auspice of the University of London and the British Postgraduate Medical Federation at the Cardiothoracic Institute Brompton Hospital, from 4 to 7 February 1985. This course is for pathologists and for chest physicians, radiolog: ists, and other non-pathologists, consisting of four days of lectures, microscopy workshops, and demonstrations. The course fee will be $£ 185$ (inclusive of coffee, lunch, and tea)@ Application forms are available from the Dean's Office Cardiothoracic Institute, Brompton Hospital, Fulhano Road SW3 6HP (01-352 8121 ext 4187).

Respiratory medicine: pharmacology and therapeutics A four and a half day course of lectures and demonstra $N$ tions on current aspects of respiratory pharmacology and treatment will be held from 25 February to 1 March 1985 at the Royal Postgraduate Medical School, Hammersmit Hospital, London, W12 0HS. Topics include asthmamechanisms and treatment; protease-antiprotease ba ance in chronic obstructive lung disease; treatment of alveolitis, cystic fibrosis, and opportunistic infections; antis? biotics; cancer chemotherapy. The course organisers are Drs PJ Barnes and NB Pride. Course fee (including catering) $£ 160$. Application forms and further details may be्D obtained from School Office (SSC), Royal Postgraduate Medical School, Hammersmith Hospital, Londo W12 0HS (01-743 2030 ext 351). 